\title{
Deadness
}

\section{Technologies of the Intermundane}

\author{
Jason Stanyek and Benjamin Piekut
}

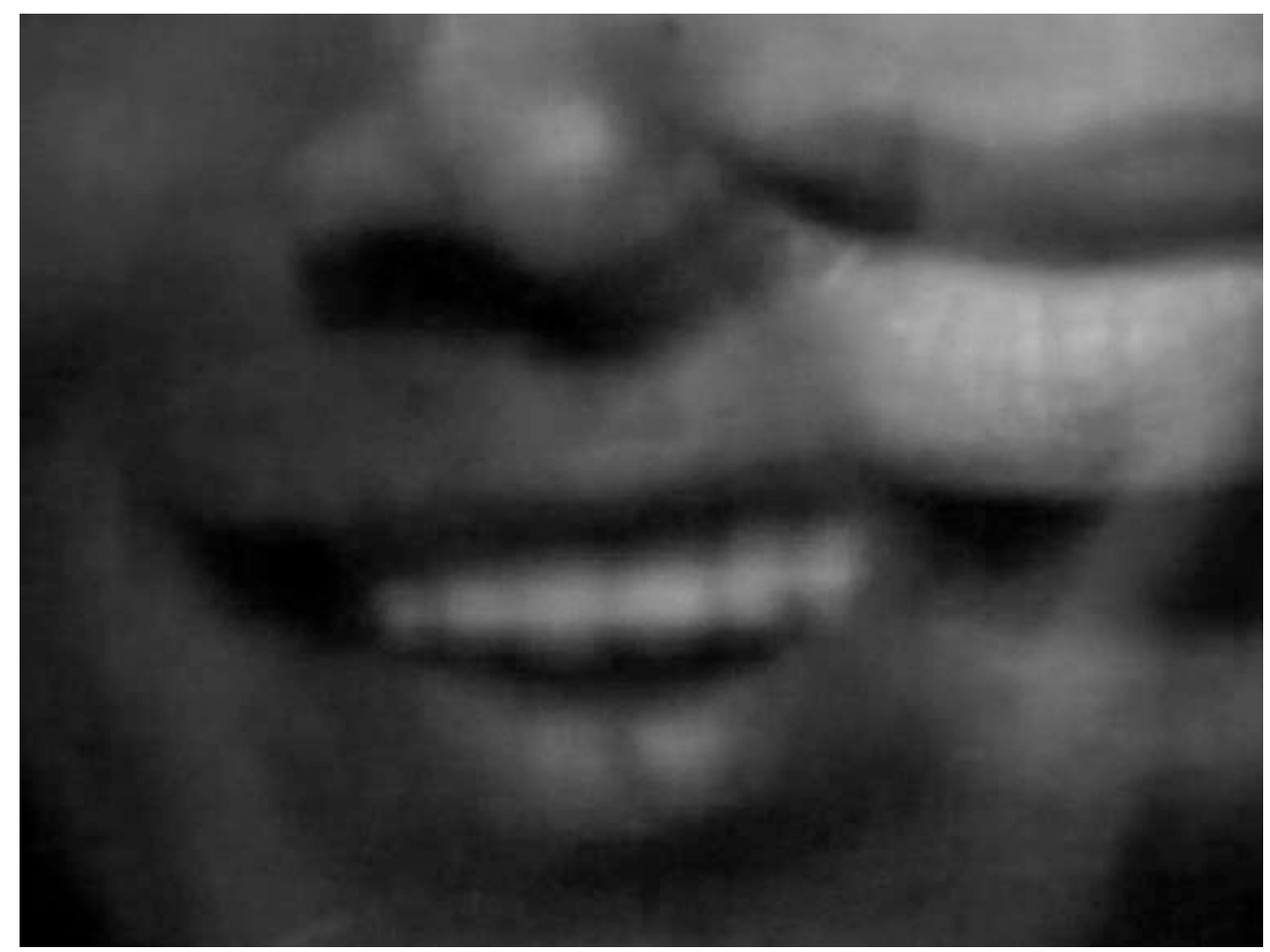

Figure 1. A meeting of mouths, from Natalie Cole, Unforgettable, directed by Steve Barron. New York: Elektra Video, 1991. (Screen shot by Jason Stanyek and Benjamin Piekut)

In late capitalism, the dead are highly productive. Of course, all capital is dead labor, but the dead also generate capital in collaboration with the living. What is "late" about late capitalism could be the new arrangements of interpenetration between worlds of living and dead, arrangements that might best be termed intermundane. As Joseph Roach writes, "modernity itself might be understood as a new way of handling (and thinking about) the dead," but the mechanisms and procedures through which this handling takes place are under constant revision (1996:14). While Roach is concerned with mapping "a revolutionary spatial paradigm: the segregation of the dead from the living" (48) in early modern Europe and its colonies, we are interested in a later arrangement of bio- and necroworlds, one centered on production of several kinds: social, economic, cultural, and affective. In this arrangement, the living do not one-sidedly handle the dead, but participate in an inter-handling, a mutually effective co-laboring. 
"Death isn't the end," remarks Mark Roesler, the CEO of CMG Worldwide, an intellectual property management company that plays an important role in the growing field of "necromarketing" (in Hoffman 2005). ${ }^{1}$ In what could be seen as a case of millennial anxiety over the reconfiguration of labor in a burgeoning necro market, Forbes in 2001 began publishing their annual list of "Top Earning Dead Celebrities," which for the past seven years has been fleshed out by a barely rotating cast of actors, writers, artists, and musicians: Marilyn Monroe, Charles Schultz, J.R.R. Tolkien, Andy Warhol, John Lennon, and Bob Marley, among others. Without doubt, Elvis is the king of the dead, topping the list for six of the past seven years, and earning between \$35 and \$50 million annually in publishing, Graceland tourism, and licensing and merchandising fees. ${ }^{2}$

The revivification of celebrities has become a key tactic in advertising campaigns for global product lines-John Wayne yuks it up with a pair of thirsty losers for Coors; Fred Astaire gets down with a Dirt Devil vacuum cleaner; Audrey Hepburn cuts a rug for the Gap; and Louis Armstrong, Humphrey Bogart, and Jimmy Cagney enjoy a wild Diet Coke party with Elton John. "Would you believe this little baby holds 30 gigs?" asks a digitally reanimated Orville Redenbacher (who crossed over in the pre-iPod 1990s) in one recent advertisement, hoping to capitalize on the rather oblique relationship between an ultra-thin MP3 player and ultra-fluffy popcorn (see Beard 1993 and 2001; and Anderson 2004/2005).

Music has been a particularly fertile growth market for dead talent. Although "Unforgettable," the 1991 Grammy Award-winning collaboration between Natalie Cole and her then almost 30-year-dead father, is undoubtedly the essential example of what has variously been referred to as "electronic deception," or "manufactured," "virtual," "simulated," or "studioengineered" duets, ${ }^{3}$ the recording capitalized on a tradition that included Hank Williams Jr. and Sr.'s "There's a Tear in My Beer" (which won a Grammy Award for "Best Country Vocal Collaboration" in 1990), and Jim Reeves and Patsy Cline's "Have You Ever Been Lonely (Have You Ever Been Blue)" of 1981 (Zimmerman 1989 and Hilburn 1981). The latter collaboration

1. In 2005, one marketing research company reported that advertisements featuring dead celebrities had doubled in the last 10 years (see Guthrie 2005; see also Gardner 2006).

2. The only exception to Elvis's reign at the top came in 2006, when Courtney Love sold a 25 percent stake of her holdings in Kurt Cobain's back catalog, thus netting a huge profit for the late Mr. Cobain. For the most recent Forbes list see Noer, Ewalt, and Hoy (2008). Michael Jackson's death in June 2009 will undoubtedly mark the emergence of a new necrophonic superstar. "This Is It," his first posthumous single, was released only four months after his death, and during an elaborately choreographed tribute at the MTV Video Music Awards (held in September 2009 in New York City), he appeared in a duet with his sister Janet, dancing to their song "Scream."

3. For "electronic deception," see Toop (1991); for "manufactured duet," see Zimmerman (1993); for "virtual duet," see Melloy (1999); for "simulated duet," see Farber (1999); for "studio-engineered duet," see Tabor (1994).

Jason Stanyek is Assistant Professor in the Department of Music at New York University and was recently a Visiting Associate Professor at Harvard University and an External Faculty Fellow at the Stanford Humanities Center. He has published on subjects ranging from Brazilian hip-hop to PanAfrican jazz, from intercultural free improvisation to capoeira, and is at work on three book projects: an ethnographic monograph on Brazilian performance in the US; a coauthored book (with Benjamin Piekut) on "posthumous duets"; and a coedited volume (with Sumanth Gopinath) entitled The Oxford Handbook of Mobile Music Studies. Also active as a composer, guitarist, and cavaquinho player, he has a number of recordings and film soundtracks to his credit.

Benjamin Piekut is Lecturer in Music at the University of Southampton, England. He teaches units in pop, jazz, and cultural studies, and is preparing a book on experimental music in New York during the 1960s. He wrote a chapter on composer/activist Henry Flynt for the collection Sound Commitments (Oxford University Press, 2009), and is the author of two articles on the Jazz Composers Guild, forthcoming in Jazz Perspectives and American Quarterly. 
enjoys special status as perhaps the first duet to have been recorded after both of its partners were dead. The success of "Unforgettable" also set in motion a wave of collaboration CDs, including tributes to Bob Marley (Chant Down Babylon, 1999), Dean Martin (Forever Cool, 2007), and Notorious B.I.G. (Duets: The Final Chapter, 2005), as well as numerous individual tracks pairing David Byrne and Selena ("God's Child [Baila conmigo]," 1995), Kenny G and Louis Armstrong ("What a Wonderful World," 1999), The Beatles and John Lennon ("Free as a Bird," 1995), Brian and Carl Wilson ("Soul

What is "late" about late capitalism could be the new arrangements of interpenetration between worlds of living and dead, arrangements that might best be termed intermundane.
Searching," 2004), and a new track by Anita Cochran ("[I Wanna Hear] A Cheatin' Song," 2004) that used previously recorded material by Conway Twitty to construct new vocal lines that he had never actually sung in the first place. ${ }^{4}$ Two dead artists have been particularly prolific. Frank Sinatra's 1999 duet with Celine Dion, "All the Way," and his more recent collaboration with Alicia Keys

("Learnin' the Blues," which kicked off the 2008 Grammy Awards show) pale in comparison to Sinatra at the London Palladium, a complete revue that ran for seven months in 2006 and featured Old Blue Eyes accompanied by a 24-piece orchestra. ${ }^{5}$ Pac's posthumous albums have sold over 20 million copies and eight of these have been certified platinum. The bulk of these albums feature posthumous duets with living hip-hop artists and the soundtrack to the biopic film Resurrection even has him and the similarly deceased Notorious B.I.G. dueting on the track "Runnin' (Dying to Live)" (2003). ${ }^{6}$

Sound-recording technologies have always been associated with death. While Jonathan Sterne argues that sound recording in the 19th century "preserve[d] the bodies of the dead so that they could continue to perform a social function after life" (2003:292), we are concerned with a different arrangement of technologies and bodies that is less about preservation than it is about complex forms of rearticulation. If the late-19th-century urge was to embalm (sounds floating, inert, in the formaldehyde of tin, wax, or resin), since World War II, the tendency has been to recombine. This is the age of the splice, and this recombinatorial imperative emerges on

4. Twitty's part was pieced together the old fashioned way — with bits of analog tape. Soon, however, producers will be able to use software to emulate any celebrity voice (see Guernsey 2001).

5. The orchestra performed new arrangements of Sinatra's best-known tunes. Many of the Sinatra performances that feature in the show "are taken from a trial recording for a television special featuring just Sinatra and [Bill] Miller. From this it has been possible to add live musicians and dancers," writes Spencer Leigh (2006).

6. The list goes on: Ann and Paul Downing ("Are You Tired," 2004); Deborah Allen and Jim Reeves ("Don't Let Me Cross Over" and "Oh, How I Miss You Tonight," 1979); Brad Paisley and Buck Owens ("Hello Trouble," 2008); Anne Murray and Dusty Springfield ("I Just Fall in Love Again," 2008); The Bee Gees and Andy Gibb (“Immortality," 1998); Lisa Marie and Elvis Presley (“In the Ghetto," 2007); Gunther Neefs and Louis Neefs ("Laat ons een bloem," 2000); Christopher "CJ” Wallace, Jr., Faith Evans, and The Notorious B.I.G. ("One More Chance/The Legacy [Remix]," 2008); Mark Weigle and Steve Grossman (“Out,” 2002); Charles Aznavour and Edith Piaf ("Plus Bleu Que Tes Yeux," 1997); Olivia Newton John and Peter Allen ("Tenterfield Saddler," 2002); Lorrie Morgan and Keith Whitley ("Til a Tear Becomes a Rose," 1990); Natalie and Nat King Cole ("When I Fall in Love," 1996; and "Walkin' My Baby Back Home," 2008); Katie Melua and Eva Cassidy ("What a Wonderful World," 2008); Alison Krauss and Keith Whitley ("When You Say Nothing at All,” 1994). Albums of posthumous duets not mentioned above include Minnie Riperton (Love Lives Forever, 1980); Elvis Presley Christmas Duets, 2008; Clara Nunes (Com Vida, 1995); Miles Davis (Evolution of the Groove, 2007); Shooter and Waylon Jennings (Waylon Forever, 2008). The posthumous duet phenomenon has been trenchantly satirized by Saturday Night Live ("Natalie Cole Sings the Songs of Dead People," 1992) and Dave Chappelle (“Tupac's New Song in the Club," 2006). 
the corporeal plane, broadly by the end of the 1950s, with the structural modeling of DNA, the standardization of life-support technologies, and the development of immunosuppressive organ transplant procedures. In the technosonic realm, the logics of recombination surface in multitrack tape technology and begin to recondition the very nature of global musical production. In each of these cases, technologies of the body refigure component parts- the DNA strand, the disabled or transplanted organ, the voice-into networks that extend beyond self-contained limits. In this essay we peer into this environment of emergent extensities to consider the recombinatorial sonics of intermundane collaboration.

We situate this project within a body of literature on the effective presence of the dead (Castronovo 2001; Derrida 1994; Fuss 2003; Gordon 1997; Peterson 2007; Rayner 2006; Verdery 1999; Jones and Jensen 2005). The general subject of posthumous duets engages and extends this literature by setting in motion a large number of concerns, including the poetics of modern bereavement; kinship patterns; the legal and commercial structures of celebrity and property; interanimations of voice, body, and identity; and medical discourses of cryogenics, cloning, transplantation, and bioethics. Though we address these concerns in a current book project, our prevailing interest in this article is the history of recording practices from the late 19th century until the early 1990s, and the contingent arrangements of bodies, technologies, and sounds that take shape through these practices.

Although countless posthumous duets have appeared in the last two decades, our touchstone here is the Coles" "Unforgettable" (Cole 1991a). The track is important for a number of reasons beyond its Grammy-winning, multiplatinum status. Recorded in 1991 at the moment when music production made its final transition to full digitality, "Unforgettable" is a liminal document. Although sampling, digital instruments, automated mixing consoles, and even digital audiotape were commonplace by this time, it was not until the early 1990s that most aspects of production became digitized. As we detail below, "Unforgettable" participates in somebut not all—of these changes. For example, had the song been produced just a few years later, engineers would have employed visual editing applications such as Pro Tools, in contrast to long traditions of aural editing. " "Unforgettable" thus stands at the end of a long history of analog recording reaching back to the late 19th century. Tracking this history to the early 1990s, our task here is not to give a complete overview of the posthumous duet phenomenon (intermundane collaboration in the digital era, for example, requires separate treatment), but to uncover a theoretical apparatus from the long history that culminates with "Unforgettable."

There is nothing new about selling the dead to the living. In the popular music marketplace of the early 1990s, one way this activity took shape was through re-releasing the stars of the early LP era on CD or repackaging their personas in novel ways. But "Unforgettable" is different. The song may appear to be a straightforward record that is, like much popular music produced in the US after the mid-1960s, the simple result of overdubbing new tracks on top of previously recorded tracks. Our analysis suggests, however, that "Unforgettable" raises questions that are much more profound.

\section{Agency as Effectivity}

One question we continually encounter when sharing our ideas about posthumous duets with other scholars should be addressed from the very beginning. That question is, How are these

7. Al Schmitt, the engineer of the "Unforgettable" track, made clear the practical ramifications of the shift in discussing his work on Dean Martin's 2007 posthumous duet recording Forever Cool: "We were able to move stuff around, and it was just easier to try in things" (2007). Of course, engineers had long "eyeballed" analog recording tape and used visual markers while performing edits. Visual hegemony is not complete, however, until sounds move on screens. 
"collaborations" when the dead cannot respond, cannot change or adapt to their living counterparts? We contend that this question is already hemmed in by certain presuppositions about agency, many of which assume a stable and reduced ontological backdrop woven out of theories of resistance, reinscription, refiguration, and emancipation. For us, agency is not merely an individual's capacity to respond to changing conditions. "Crucially," as Karen Barad argues, "agency is a matter of intra-acting; it is an enactment, not something that someone or something has" (Barad 2007:178; emphasis in original). By "intra-action," Barad means to stress that "agencies are only distinct in a relational, not an absolute, sense, that is, agencies are only distinct in relation to their mutual entanglement; they don't exist as individual elements" (33). We take it as axiomatic that agency is always distributed and never coterminous with a single body; it is not something that a person collects and, in a moment of purposeful clarity, unleashes. Barad continues, "Intra-actions include the larger material arrangement [...] that effects an agential cut between 'subject' and 'object' (in contrast to the more familiar Cartesian cut which takes this distinction for granted). That is, the agential cut enacts a resolution within the phenomenon of the inherent ontological (and semantic) indeterminacy" (139-40). Although tempted to adopt Barad's language and refer to these posthumous duets as "intra-mundane," we retain the "inter" prefix to draw attention to the performed naturalization of the separation of living and dead mundanities, the continual production of an agential cut that assigns prime mover status to living humans while objectivizing the "dead" as inert, without futures, and non-effective.

Standard reckonings of agency are also limited by temporal orientations that privilege the present and the future, and often constrict causality to a "here and now" operation. What of distended pasts that swell up with delays, pre-echoes, calls, and incitements that spill over into multiple presents and futures? This is one of the key points of the intermundane-we can't ascribe with any certainty a direction to temporal flows; performative notions of straightforward intention and unidirectional purpose only come into being within nonlinear temporalities. The topology of causality cannot be reduced to a one-to-one relationship between action and result, for effectivity is enacted by intra-active and overlapping agencies in a manner that exceeds commonplace notions of intentionality. Effects are unpredictably durative, and can be indirect, delayed, unintended, and even unmarked. We might even say that this is the only guarantee that sound recording offers: being recorded means being enrolled in futures (and pasts) that one cannot wholly predict nor control. Crucially, having a future means having an effect. As Bruno Latour tells us, "An actor that makes no difference is not an actor at all" (2005:153).

Having a future, having an effect, making a difference. We are now drawn to the notion of effectivity, where "having" an effect is not understood in a proprietary sense, but rather as the enactment of agencies that make a difference-through making a difference, by having an effect, an agency is delineated. In a recording collaboration, what has effects? Certainly, not just living humans, all fleshy and present; sounds, machines, discourses-all manner of nonhumans, material and nonmaterial-also matter. This is not to argue for or against technological determinism; it is to say that effects are generated and absorbed by all kinds of entities. Importantly, these entities are enacted through mutual effectivities. They do not preexist their enrollment in temporary assemblages, but are constituted, diffracted, translated, and variously deferred by other agencies in these assemblages.

Moving beyond human exceptionalism by framing agency as effectivity allows us to rebuild the idea of personhood to encompass far more than a simple body or a hunk of flesh, as if personhood could be limited to the boundaries of the epidermal wall. In our framing, personhood is not equivalent to a lone body, but is distributed among and articulated with other entities that are textual, technological, juridical, and affective (for a similar approach, see Strathern 1992 and 1988). Personhood is always collaborative, cutting across clear distinctions of materiality/ discourse, technology/organicity, and bounded lifetimes/eternal deaths. We mention "bounded lifetimes/eternal deaths" because agency as effectivity is not only unpredictably durative; it is also distributed among entities that have different capabilities, resources, and "lifetimes." To say 
"personhood is distributed" does not mean that all entities within distributed assemblages have equal and unrestricted access to all possible forms of allocation. Translations, diffractions, and deferrals happen precisely because of unwanted intrusions and interferences, disproportionate rights, uneven abilities to wield force and shape outcomes. Personhood is distributed, but this does not mean that all modalities of distribution are ethical, a point to which we will return at the end of this essay.

Our primary focus is on how this agential cut of the intermundane is performed in the sonic practices of the recording studio, where collaboration is now understood to involve humans and nonhumans, all distributed and all effective. This perspective runs counter to the common understanding that collaboration necessarily entails face-to-face encounter, where participants can reach unanimity, supported by an equivalence of input and capacity. There is also an expectation of synergy or transcendence-the result of a collaboration will be magical and more than simply the sum of its constitutive inputs. Actual recorded collaborations, however, reveal numerous and even contradictory allegiances among emerging agencies, practices of temporal and spatial discontinuity, and asymmetrical distributions of power and ability. Intermundane collaborations are no different.

In this article, we generate a series of terms that have emerged out of our engagement with intermundane collaborations; although we discuss these terms in greater detail later in our analysis, we present them here as a kind of pre-echo: revertibility, recombinatoriality, rhizophonia, corpauralities, perforation, leakage effects, and deadness. Revertibility refers to a temporal process of undoing a work of recording in some way, whereby presumptive wholes can be disarticulated and taken back to a prior stage in a process of assemblage, upsetting straightforward, cumulative forms of co-labor. As we will show, there are varying degrees of revertibility in the history of sound recording and reproduction. The related concept of recombinatoriality, on the other hand, describes the capacity toward articulating what are taken to be discrete, nonidentical parts into new arrangements. Recombinatoriality is a general tendency or imperative that emerged in technology-saturated post-World War II environments, and its specific surfacing in the context of sound recording assumes (1) that elements are defined by the breaches between them and (2) that these breaches can be sutured.

Rbizophonia describes the fundamentally fragmented yet proliferative condition of sound reproduction and recording, where sounds and bodies are constantly dislocated, relocated, and co-located in temporary aural configurations. We don't offer up rhizophonia as schizophonia's other, to use R. Murray Schafer's well-trodden term (1977). It's not the missing twin. Rather, we suggest it as a replacement for schizophonia, itself a problematic, tautological term that seems to describe an exception (sound severed from source) to some impossible, full presence (sound as identical with its source; see Sterne 2003:20-21). Indeed, schizophonia describes sound itself. All sounds are severed from their sources—-that's what makes sound sound. Rhizophonia is our term for taking account both of sound's extensity and the impossibility of a perfect identity between sound and source.

To account for human positionings within rhizophonic structures, we offer the term corpauralities to describe the imbrication of sounds with fleshy bodies. Humanly made sounds are never devoid of bodies, and there is no body that isn't constituted through sonic formations. However, corpauralities are not simply traces or residues of prior sonic acts-we're more concerned with the proleptic condition of corpaural assemblages than we are with the mere persistence of a prior sounding. In our discussion of the recording studio that follows, we use the idea of the corpaural not simply to call attention to the relation between sounds and individual bodieswhat might be called "sonic bodies"- but also the ways that these corpauralities infuse with and cling to others. In this sense, the corpaural helps to sonify the idea of distributed personhood that we develop here.

Of course, there are limits to distribution, and rhizophonic structures don't proliferate in any which way; the production of corpauralites is always managed and contained. Obstacles and 
blockages can interrupt flows, or flows can traverse obstacles through certain well-defined openings, which we call perforations. A perforation controls and focuses flows between two spaces, but maintains separation between them. In the recording studio, sonically sealed spaces such as the control room or the vocal isolation booth depend on perforations that channel sound from one area to the next.

But sound can and does escape its assigned channels. For example, a sound might leak from one instrument into a microphone intended for another, separate sound source. Any of the possible responses to this leakage-separating the sources further in space, partitioning them with baffles or even walls, or recording the two sounds at different times and later recombining them on tape-is what we call a leakage effect. More schematically, leakage effects occur when an activity in one area expands unexpectedly into another area, setting in motion a second process, project, or concern. This "setting in motion" often conditions an unforeseen act of translation or transference from one realm to another.

\section{Deadness emerges out of what is}

for us an unhelpful and overvalued schism between presence and

absence that undergirds much literature on performance.
Taken together, these terms-revertibility, recombinatoriality, rhizophonia, corpauralities, perforation, leakage effects-come together under a broader frame that we call deadness. It's not our intent to raise (or even raze) one more binary, so we do not conceptualize deadness as the other to liveness. Rather, deadness emerges out of what is for us an unhelpful and overvalued schism between

presence and absence that undergirds much literature on performance. Deadness speaks to the distended temporalities and spatialities of all performance, much the way all ontologies are really hauntologies, spurred into being through the portended traces of too many histories to name and too many futures to subsume in a stable, locatable present. As we will argue below, the topologies of deadness-those never-ending emplacements within concatenations of displacements-are patterned and repatterned through specific arrangements of co-labor, or the interpenetrating, distributed effectivities of all entities that have effects. In our understanding, deadness describes the necessary choreographies of all productive encounter, and by exploring it here we hope to enlarge (albeit tangentially) the conversation in Marxist scholarship concerning dead and living labor. As Dipesh Chakrabarty explains, "Marx would ground resistance to capital in this apparently mysterious factor called 'life" (2000:60). In Chakrabarty's historical analysis, the living worker always carries with him unique histories, dispositions, and habits, "ways of being human [...], acted out in manners that do not lend themselves to the reproduction of the logic of capital" (67). Our investigation into the intermundane suggests an extension of this important point - that not only living human workers, but also the ostensibly "dead" labor of technology and discipline, and even the "dead labor" of the human dead - contains within it the seeds of unpredictable futures that can and do retrace worlds. Although the idea of deadness arose out of our analysis of posthumous duets (and, as shall be made clearer below, out of our inquiries into the dead spaces of recording studios themselves), its usefulness extends beyond the sonic realms of musical production to all kinds of co-labor.

The six concepts introduced above are integral to deadness. The paired terms revertibility and recombinatoriality refer to the sedimented pasts and possible futures of any contingent assemblage, and call attention to the ways in which these assemblages can be dis- and reassembled. Rhizophonia describes the perpetual non-identity of sounds and their sources. Corpauralities consist of anterior corporeal states that are registered in sound and anterior sonic states that are registered in the body - put simply, every sounding body will be taken up by another. Lastly, the entwined terms perforation and leakage effects suggest that attempts to regulate passages from one state to another are thwarted, always necessitating ever-new forms 
of containment. In the following condensed history of sound technologies and their related practices, these terms emerge in more concrete examples as we trace the shifting topologies of deadness in the necro-sonic realm of the recording studio.

\section{A Technogenealogy of the Intermundane}

It is commonly understood that the arrival of multitrack technology in audio recording of the 1950s effected a major shift in the aesthetics and ontologies of musical production. Individual instruments or voices could now be isolated, moved around, and equalized separately-the sonic text was conceptualized in layers. However, we agree with Paul Théberge when he suggests that "layering techniques appear to have historical precedents that antedate multitrack recording by many years" (1997:217).

In the 1940s overdubbing began to emerge as a viable technique for the production of commercial recordings. Sidney Bechet recorded two "one-man band" sides in 1941—“The Sheik of Araby" and "Blues for Bechet" (Parmenter 1941)—and by 1947 Patti Page used overdubbing technology to create a duet with herself on the song "Confess" (Sutheim 1989). ${ }^{8}$ About a year later, the guitarist Les Paul scored a few minor hits with "Lover" (1948) and "Brazil" (1948), both of which featured him on a number of different instruments (Doyle 2005:147). These kinds of overdubbing practices built the final mix one pass at a time- the previously recorded take was played back on a phonograph, the signal of which was mixed together with the next live part, and then fed into the disk recording lathe. ${ }^{9}$ Paul switched to tape in 1950, customizing his Ampex Model 300 full-track tape machine with a fourth playback head, allowing him to monitor his previously recorded tracks while overdubbing a live performance..$^{10}$ After a new part was added in this way, it was locked into the mix and could not be edited or processed separately-once recorded, the individual parts could not be recuperated and disarticulated from the whole; parts could only be added, not taken away. According to the standard narrative, what we are calling revertibility would not become a feature of recording until the multitrack tape era about a decade later. ${ }^{11}$

But it's messier than that. The history of sound recording cannot be reduced to a teleological unfolding from the "capturing" of live performances to "overdubbing" to "multitracking." Nor can we say that processes of revertibility didn't exist until the 1950s. Take the example of what might be the first intermundane collaboration in popular music, and indeed one of the first examples of overdubbing: tenor Enrico Caruso's 1932 recording of "Vesti la Giubba," from Leoncavallo's I Pagliacci (Pakenham 1932). As is well known, Caruso was the biggest recording star of the acoustic era, a fact many attribute to the close fit of his voice into the narrow frequency range of the phonograph-his 1907 version of the aria sold more than one million copies (Eisenberg [1987] 2005:120-23). The introduction of electric microphones in 1925 had led to great advances in recording fidelity, and Victor sought to re-release the popular disc in 1932, even though Caruso had died 11 years before. Displeased by the small-sounding and faint

8. In 1950, Page also overdubbed multiple versions of her own voice on "With My Eyes Wide Open I'm Dreaming," an example of what Peter Doyle calls “'equal partner' sonic doubling” (2005:152).

9. In the case of Page, the final recording pass was made onto a wire recorder (Sutheim 1989:730).

10. Paul arranged four heads in the following order: playback-erase-record-playback. The added playback head, situated in the first position in sequence, routed his previously recorded material to the record head along with the live take. The second playback head allowed Paul to monitor his new layer in the complete mix. Unlike overdubbing on disc, where a flawed take would only result in the trashing of the record disc, leaving the previous generation untouched on the playback machine, the magnetic tape process was truly non-revertible. A mistake ruined everything, and the song had to be rebuilt from the beginning (Snyder 2003).

11. And even in the multitrack period, nonrevertible overdubbing processes were often used in combination with multitrack technology. 
accompaniment, the company's engineers used an early form of equalization to attenuate the highest and lowest frequency ranges on the original disc, thereby stripping away the accompaniment from the 1907 recording and leaving space to "underdub" a new orchestral backing behind Caruso (Millard 1995:286). A 1932 short film, titled "Voice Grafting-The Latest Miracle of 'Sound' Science," takes us into the studio to explain how it was done: the camera points out from the machine room past an engineer who is working at a recording device. We peer through the isolation window and see a headphoned conductor in front of his orchestra, listening to the newly equalized 1907 disk and leading the ensemble's performance of the new accompaniment. As the announcer of the film exclaims, "Now, for years, recording engineers have been attempting to find some way by which the voice of Caruso could be re-vitalized and the true beauty and dramatic fervor brought out. And at last, they have succeeded" (Pathé Pictorial 1932).

Indeed. This may very well be the first case of a dead performer recording with live musicians, and its success was driven by two linked, indeed inseparable processes-one articulative and the other disarticulative. The joining of Caruso with a new set of collaborators over a decade after his death depends on, even necessitates, the removal of his 1907 musicians. Articulative overdubbing and disarticulative equalization are conjoined. The crucial point here is not simply that this is a very early example of overdubbing (preceding Bechet by nine years), but that the overdub itself relies on a disarticulative process of equalization that is an early example of the kind of revertibility thought only to be possible with multitracking, and (as we'll soon show) acoustic isolation. Here we latch on to Théberge's point that layering techniques antedate the multitrack era, and that the very idea of overdubbing is "rooted in the technology of mechanical reproduction itself" (1997:217).

The argument we are pursuing here proceeds along a different track from that of authors like Allen S. Weiss and Evan Eisenberg, who write eloquently about the aural ruptures and disembodiments produced by sound recording (Weiss 2002; Eisenberg [1987] 2005). Unlike these studies (and many others), we are interested in rhizophonic emplacements and displacements within contingent aural configurations. The idea of cotermineity-or, shared temporal and spatial boundaries- that is embedded in the aesthetics of capture is always an internally segmented unity. Cotermineity is never what it seems to be; even in early recording situations where "capturing" a live performance is the fundamental goal, there are always lags, leaks, and perforations that are indicative of intricate spatial and temporal enfoldings and defoldings. In the period leading up to, and immediately after, Caruso's 1932 intermundane recording, numerous examples illustrate the rhizophonic character of sound recording and reproduction, and their entanglement within segmented wholes and discontinuous temporalities.

In 1888, Edison and his assistants set up the first recording studio on the top floor of his West Orange, New Jersey, laboratory (Millard 1995:258). After initial experiments, the large open room was divided by a wooden partition, perforated only by the phonograph horn poking through. ${ }^{12}$ By the time Edison, Columbia, and Victor built custom studios around the turn of the century, equipment was set off in an isolated control booth, the first step in the everincreasing spatial segmentation of recording studios (Morton 2000:19). Partitioning disarticulated the bodies of engineers from those of the performers, as well as those spaces marked as "technological" from those signifying "music." These partitions were constructed in order to be bridged-the phonograph horn reconnects divided spaces, rearticulating the separated parts into the newly assembled unity of the etched groove. But it's equally important to stress that this articulated unity does not do away with the isolation of these parts. The horn poking through the partition connects two discrete spaces while simultaneously keeping these spaces separate. The horn perforates rather than simply unifies. Isolation needs perforation. From the very beginning, recording studios have been perforated environments that favor a seemingly paradoxical co-process of connection and disconnection.

12. For a photo of the studio, see Kraft (1996:233). 
A more subtle logic of segmentation was already at work on the level of soundwaves themselves. As Emily Thompson has shown, architects throughout the 18th and 19th centuries were concerned with controlling the acoustical properties of large spaces (2002:13-57). Sound was conceived of as the result of combinations of component parts-reverb and echo were to be eliminated, disarticulated from the sonic totality. By the time of the publication of Hermann Helmholtz's On the Sensations of Tone in 1863, it was well known that what was perceived as a single sound was in fact a composite system of distinct parts. Acoustic treatment might be thus understood as a form of proto-equalization or parametricization that was used to accentuate certain frequencies and deemphasize others.

This manner of conceptualizing sound is specifically reflected in the way early recording studios were modified to diffuse sound waves, strip reverberation, and eliminate certain spectra. "Reverberation was the bane of early recording sessions, and most studio

Isolation needs perforation. From the very beginning, recording studios have been perforated environments that favor a seemingly paradoxical co-process of connection and disconnection. surfaces were well-padded" with cow hair, seaweed, draperies, and horsehair (Morton 2000:20-21; see also Millard 1995:259-60; Welch and Burt 1994:169). Modulating the acoustic properties of recording spaces continued after 1925, when electric microphones were introduced into the process.

The parametric logic that was applied to sounds was also applied to human bodies, whose distribution within recording spaces varied as new technologies developed from the single-sited portal of the recording horn to the multi-sited virtual portal of an array of microphones. The recording horn had a limited ability to capture distant sounds, and for this reason studios tended to be small and musicians were typically cramped together as close as possible to the opening of the horn. In terms of fidelity, recordings of solo performers and small groups were the most successful. The shift to electric microphone technology in the 1920s allowed new human spatial configurations to emerge, as the horn's single portal was now multiplied into several: the signals of multiple microphones were mixed together and cut into one channel on a disc in the studio. This innovation was imported from radio dramas, where each character spoke into a separate microphone, through the film industry, and finally into sound recording (Millard 1995:272). In 1926, the New York Times described the first instance of multi-miking by Warner Bros. in the Manhattan Opera House, referring to the mixing console-a relatively new piece of equipment for the general public —as a "switchboard": "[W]hile the artists gave their numbers on the stage the voices and instrumentation were carried by acutely attuned transmitters [i.e., microphones] through wires into a complicated switchboard and then made 'fast' in the laboratories" (New York Times 1926; see also Millard 1995:285, and Thompson 2002:268).

Warner Bros. had long been searching for a way to synchronize sound to motion pictures, and in the months before this event had commissioned a test that necessitated the conversion of the opera house into a studio-seats were removed, the stage was enlarged, and control booths and repair shops were installed in the theatre boxes. Cables ran through the ventilation ducts (Frayne et al. 1976:516). Two sample recordings of the overtures to Richard Wagner's Tannbäuser and Ambroise Thomas's Mignon were simultaneously created: one with a single microphone, and another with an array of six-one overall, plus one each for violins, celli and basses, brass, woodwinds, and percussion (517). When the two recordings were compared, the multiple pickup was agreed to be superior. Despite this early example, however, multi-miking took years to catch on in sound recording. Unlike in the film industry, where sound engineers were ensconced at the mixing desk by the late 1920s, the large music recording studios rarely used multiple microphones until the end of the 1930s (Millard 1995:275). 
Regardless of the kinds of isolation techniques that were used for separating sound sources or the microphone placement schemes that helped produce different dynamic levels for different instruments, mixing was still done live and was a non-revertible process. Sounds were routed into microphones, through mixing boards and into single-track recording devices. In the music industry, multiportality did not come to be seen as a mechanism for creating multiple, mixable, and indeed revertible tracks until the adoption of multitrack tape recorders in the 1940s and 1950s. ${ }^{13}$ The film industry, on the other hand, was fully invested in multitracking by the early 1930s (O’Brien 2005:111). Indeed, Nathan Levinson's 1933 article in American Cinematographer notes that "at Warner Bros.—a famously cost-conscious studio- 'as many as sixteen separate sound tracks, each one carefully controlled as to level, perspective and quality [were used] to make a pleasing composite soundtrack"' (1933:6-7). More importantly than just marking the ability of sound engineers to concatenate various sounds together to produce a film soundtrack, this article gives insight into the logic of revertibility that was crucial during this early stage of multitrack recording, especially after Warner Bros. had converted to recording sound entirely on film. "By that time the development of automatic equipment had been developed to such a high state that it was possible to scramble a ten-syllable word and bring it back to its original form at will," Levinson wrote (6).

The music industry began recording on single-track (or "full-track") magnetic tape shortly after the US military brought the technology back from Germany following World War II, with the first machines becoming commercially available in 1948. By the early 1950s, there were two-track ("half-track") and even three-track recorders, but these machines couldn't record channels separately, and any recording made with these machines needed to be done "live." Discrete mixing of channels was possible when the multichannel tapes were mastered into mono (at the time, still the dominant consumer format), but once a recording was made, overdubbing another track was virtually impossible. The key issue was synchronization. In the case of three-track tape, playback, erase, and recording heads were stacked vertically across the tape surface. Any attempt to re-record a single track was doomed to fail because the live-recorded material was always spatially_and thus temporally_displaced from the accompanying playback tracks. In other words, the newly recorded part was always staggered from the preexisting parts, and thus when the three vertically aligned playback heads were engaged simultaneously, the track that had been added later was physically out of sync with the others.

The key technological breakthrough leading to "true" multitrack recording, wherein different parts could be recorded at different times and recombined at a later mixdown, was introduced by Ross Snyder of Ampex Corporation, in c. 1956, in consultation with Les Paul. Unlike the early multitrack tape machines that had separate stacks of recording and playback heads, the new Ampex machine-known as the "sel-sync"—combined playback and recording functions into a single stack of heads. This allowed for overdubbing musicians to monitor prerecorded tracks while they laid down new ones. As Snyder tells it, "I reasoned that a recording head [...] would serve well enough for playback that its amplified output could surely be used by an artist with headphones to hear a previously recorded track while recording a new performance part, perfectly synchronized, onto another recording head in the same vertical stack" $(2003: 211)$.

The importance of sel-sync multitracking derives from the way it established a method for recording performances that were segmentally revertible. Segmental revertibility requires

13. According to David Morton, the earliest multitrack recordings were achieved at Bell Labs in the mid-1930s using multiple optical tracks on film (2004:78). In the early 1940s, German tape recorders were modified to record two programs on a single tape, dividing the tape surface into two long "tracks" that could be recorded and played back separately (Morton 1995:431-32). In the early to mid 1950s, two-track and three-track recording devices were becoming widely available, but these were not commonly employed in music production until the late 1950s when stereo recordings became a fixture in the commercial recording industry (Schmidt-Horning 2002:216-17) 
discrete tracks, and discreteness can be achieved through temporal isolation-for example, the dissynchronous recording of single tracks that are later conjoined. But discreteness can also be attained through various forms of spatial isolation, in the synchronous recording of distinct tracks by multiple musicians who are separated architecturally. Sel-sync involved spatial isolation at the level of the recording/playback heads themselves. Snyder mentions that one of Ampex's principal innovations was the creation of "heads with rejection of track-to-track cross talk sufficient to deliver performances clearly separated" (2003:210); the very fact that the heads were stacked and extremely proximate created a rather daunting but, in the end, surmountable engineering obstacle.

In the case of cross-talk, the sound from one track (or one space or one time) leaks out and is absorbed into another. But there is another level of effectivity: the concern for creating "selective" and "synchronous" multitrack recording technology overflows itself to create a new concern for isolated tapeheads that eliminate cross-talk. Here, sonic leakage exemplifies the general principle that we call "leakage effect." As we outlined at the beginning of this article, a leakage effect names the unanticipated consequences of a process that has overflowed its conceptual boundaries, setting in motion a second process or concern-for example, the problematic noisiness of Bell and Howell cameras leading to a sharpened distinction between points of aural and visual capture in talking film production, or the emergence of new technologies such as the click track, which helped to overcome the seemingly intractable problem of creating an exact temporal correspondence between image and sound (Hochheiser 1992:280). ${ }^{14}$

We might say that at the base of the entire history of audio-visual recording-indeed, at the fundament of all electronic communication-is a culture of synchronization. Sync culture- that leakage effect caused by the awareness of temporal disjointedness-devel-

The deeply held desire to rejoin elements that have been desynced is itself a product of reproducibility, for synchronization only becomes thinkable once there is a perception that sound and image, voice and body, bodies and other bodies, have first been divided. ops precisely at the moment when non-synchronization becomes a technical hurdle. The deeply held desire to rejoin elements that have been desynced is itself a product of reproducibility, for synchronization only becomes thinkable once there is a perception that sound and image, voice and body, bodies and other bodies, have first been divided.

Whereas sel-sync managed leakage at the microlevel of the recording apparatus, outside the control room and on the other side of the glass, another kind of leakage—-sound waves from one instrument seeping over into a microphone that is dedicated to another instrument-led in the 1950 s to engineering concerns that produced methods of architectural isolation, or spatial disarticulation. Until of the advent of the multitrack machine, recording engineers typically made great use of leakage. As engineer Paul Camarata recounts in Temples of Sound:

The best rooms are not dead rooms. They just have great leakage that you can work with. We didn't have isolation [between instruments]. We all had to do things live in those days, [so] leakage, the quality of the leakage, was very important, and that separated the studios. If a room didn't have good leakage, people didn't work in them. (in Cogan and Clark 2003:48)

Milton T. Putnam tells us that in the pre-multitrack era, "Isolation screens, vocal booths, drum booths, 'gobos,' rugs and umbrellas were conspicuous by their absence" (1980:3). This formula-

14. A click track is a reference rhythm played through headphones to coordinate musicians. It is kept inaudible to the audience for the final product (whether a recording or a live performance). 
tion is intended as a kind of back-formation-Putnam is clearly thinking of the segmented spaces that studios became after the widespread incorporation of multitracking technologybut, as we've seen, the spatial partitioning of studios begins to happen at the very beginning of the recording era. All recording processes perform respatializations. By the early 1960s, however, multitracking led to an intensified proliferation of spatial segmentations in the recording studio. Vocal and drum isolation booths, in particular, became crucial for managing leakage at one stage of the recording process in order to produce new kinds of articulations at others. As Michael Rettinger wrote at the time, "acoustic separation and isolation between microphones can be obtained more readily in a dead than in a live space. This separation adds to studio flexibility and offers greater latitude in defining sections of the orchestra" (1957:18).

As segmentations proliferate so do conduits. We might say that engineering concerns that arise from the perceived need for spatial partitioning lead to the creation of new kinds of methods for drawing partitions into a network. The clean subdivisions of the studio environment-for example, rooms sonically set off from one another by glass partitions-function less as discrete spheres than as interconnected nodal points (what Alexander R. Galloway and Eugene Thacker call "modulated individuation" [2007:37-38]). According to Millard, EMI's Abbey Road was built in 1931 with three studios connected by over four miles of electric cable (1995:287). Four miles of cables, threaded through multiple rooms, rendering discrete spaces into a network. By the end of the 1950s, all studios are segmented and channeled in this way. Throughout the network are unheralded but crucial entities—shielded cables, XLR connectors, and cable snakes - that allow sounds to be routed over great distances through diffuse perforations.

Perforations punch out portals between discrete spaces, rendering them particularly indiscrete- that is, indiscrete in particular ways. These passages are punched out, and they are also punched through. But what about punching in? "Punching in" is the term recording musicians and engineers use to describe the process of recording over a short span of one track on a multitrack tape. It is more specific than a tape edit, where one piece of tape is physically cut and rejoined to another in order to cover up a mistake in the entire mix, or to join two different takes to create a more perfect whole. These are techniques that are proper to tape as a general medium, while punching in is only possible in a multitrack environment, creating an insert edit that is added "on the fly." A guitarist might punch in to the middle of her solo to fix a passage of overambitious shredding, recording over the previous take while monitoring all the other instruments in her headphones. This is different from overdubbing; the new take is not layered over all the others, nor does it replace the previous take in its entirety. From the beginning, punching in was tied to multitrack recording, and became a common practice in studios after the $1950 \mathrm{~s} .{ }^{15}$

Editing, mixing, splicing, punching in—all forms of articulation—require anterior disarticulations, whether spatial or temporal. The segmental revertibility that results from these disarticulations enables temporal flows in both directions-backward to earlier stages of the production process, but also forward to new configurations of discrete tracks. Segmental revertibility also allows spatial flows between and across discrete locations-sonic traversals from the live room, through the vocal booth, into the control room, and back out into other segmented positions. Recombinatoriality describes this environment of elaborated possibility; having been rendered discrete, isolated, or disarticulated, sounds propagate and become part of a greater network within which conditional assemblages emerge, persist, decay, and double back on themselves. The technological condition of intermundanity rests upon this base of segmented, contingent unities.

15. Information on the history of punching in was gleaned from the users of the Gear Slutz web discussion board (www.gearslutz.com), and from Armin Steiner (2008). 
The intermundane is a kind of conditional arrangement, subject to transformation no matter how immutable and perdurable it may appear. Any intermundanity is interactional and relational, and must be understood as the co-constitution of bio- and necroworlds that interpenetrate in specific ways. It is an institutional formation characterized by techniques of management (and by management we mean the active attempt to create and manage perforations and control the leakages that are inevitable within any perforated environment). Deadness is the patterning and repatterning that occurs within this arrangement; it is the labor that reinscribes but also destabilizes intermundanity; it is the very promise of recombinatorial and revertible labor; it is the coincident harnessing of the productive capacities of both living and dead, capacities that are patterned through specific forms of co-laboring. Living and dead are misnomers here: all labor enrolls dead labor and all worlds are intermundane. Our charge is to tease out the contingent patterns of collaboration within the intermundane: the apportionment of resources, the conscription of value, the deployment of technologies of co-presence, and the emergence of effective agencies, not to mention the uneven claims to ownership and refigurations of the corpaural body within the durative soundscapes of intermundanity. Intermundane collaborations enroll, enlist, and manage deadness, not from the grave itself, but from another dead space: the recording studio.

\section{Unforgetting the Dead}

It's 1961. Nat "King" Cole stands in front of a Neumann U47 microphone in Capitol's New York studio recording facility, located on the first floor of the Eaves Costume Company building at 151 West 46th Street. Nat is in the large "live room" of Studio A, joined by conductor Ralph Carmichael, who leads a small orchestra of about 25 players. ${ }^{16}$ The musicians read from Nelson Riddle's original parts for his arrangement of "Unforgettable," the Irving Gordon tune that was the basis of Riddle and Cole's first properly credited collaboration in 1951. Producer Lee Gillete circulates between the live room and the control room, where an Ampex 300M tape machine records the action onto three separate tracks.

According to Irv Joel, an engineer who worked at the Capitol Studio between 1955 and 1969, the liveliness of the live room at Capitol New York could be modulated by adjusting reversible panels made of pegboard on one side and fiberglass covered with burlap on the other. Although the room was otherwise "open," a variety of technologies combined to segment the space during a typical recording. On the 1961 date, for example, Nat was positioned behind a small gobo to shield his vocal performance from the other sounds in the space, which were captured separately by a large number of carefully placed microphones. Routed through multiboxes, these signals could be combined and sent to the control room, where they could then be mixed, equalized, or sent back out to the facility's well-regarded echo chamber. ${ }^{17}$ Located at the back of the main studio space, the chamber consisted of an approximately $20^{\prime} \times 15^{\prime} \times 22^{\prime}$ room with an inclined floor, a flat back wall, and an angled front wall. The entire chamber was covered in Keene's cement and then shellacked. Reverberation was often added on the fly during live takes by sending signals through an Altec 604 loudspeaker at the front of the chamber to a pair of RCA $44 \mathrm{BX}$ ribbon microphones at the back. This processed signal then traveled back into the control room and on to the tape recorders.

By the early 1960s the control room at Capitol New York was restructured to take account of the major shift toward stereophonic sound that was taking place in the music industry. In short,

16. The following narrative of the 1961 session is based on interviews with Irv Joel (2008) and Ralph Carmichael (2008); and Davis (1963:360-70). We are also indebted to Will Friedwald, and to Jordan Taylor of Bear Family Records for their help in tracking down information from this session.

17. A brief mention of the echo chamber can be found in Putnam: "In 1953, when Capitol completed their New York Studios, they built a superb reverberation room, which was always recognizable on records because of its excellent sound" (1980:9). 
it was divided into two control booths-one for the monitoring of mono recordings and the other for stereo. On some occasions during the early 1960s, two recording sessions took place simultaneously with parallel sets of engineers and recording equipment. We don't know if the dual control room setup was used for Nat's 1961 "Unforgettable" sessions, but these sessions certainly need to be placed within the context of this newly emergent marketplace for stereophonic recordings. Much like Victor's "revitalizations" of Caruso's early acoustic hits for the electronic era ${ }^{18}$ Capitol was taking advantage of changing sound-recording formats to wring a little more profit out of their superstar singer. Over the course of nine sessions in New York in spring 1961 (plus three more at Capitol's North Vine Studio in Hollywood during July 1961) they rerecorded 36 of Nat's previous mono hits, releasing the collection as the three-LP set The Nat "King" Cole Story. Although the Ampex 300M at the studio was not sel-sync, it did allow Capitol to take advantage of new technologies of reproduction. Three tracks of $1 / 2$-inch tape allowed engineers to place Nat's voice alone, dead center, with the orchestra on the left and right tracks. Out in the live room with the other musicians, Nat was also dead center, encased in his gobo, his microphone close to his mouth, his sonic world immediate. But there would be leakage.

It's $1991 .{ }^{19}$ Natalie Cole stands in front of a Neumann U67 microphone in the isolation booth of Ocean Way Studio A/B in Los Angeles. The booth, acoustically sealed off from the studio's other rooms, is still a perforated environment. Balanced cables connect her to the live room where Johnny Mandel leads a 55-piece orchestra, and to the control room where producer David Foster and engineers Al Schmitt and Rail Rogut monitor the music making of Natalie, Nat, and the orchestra. Each of the live performers wears headphones. The engineers send Nat's voice to Natalie, and a pre-recorded "human" click track to the conductor, rhythm section, and string players. Mandel conducts his own slightly altered version of Nelson Riddle's original 1951 arrangement, and Natalie sings in unison with her father.

This is neither the beginning nor the end of the process of creating the final track. In the early 1980s, Natalie had experimented with singing "Unforgettable" onstage as a duet with her father, ${ }^{20}$ so when she moved from EMI to Elektra in the late 1980s, the idea for her to do a record of her father's music was already in place. Like Victor in 1932 and Capitol in 1961, Elektra in 1991 was seeking to recapitalize the stored star power of residual, spectral celebrity. After Natalie and Foster worked out the initial details for creating the duet, Foster used his considerable influence in the industry to have the 1961 three-track master tape exhumed from Capitol's archive at an Iron Mountain storage facility in Glendale, California. Once the master had been taken to Capitol Studio, threaded into the same type of Ampex 300M recorder that had created the original, and transferred to 24-track tape, Foster heard, to his amazement, that the original tape was in pristine condition, with Nat's voice isolated on one of the tracks.

18. For more on record labels that revivify their dead superstars, see Eisenberg [1987] 2005:50-51.

19. Unless otherwise noted, the following narrative of the 1991 session is drawn from Cole and Diehl (2000) and Buskin (2004); and telephone interviews with Al Schmitt (2007, 2008), David Reitzas (2008), and Rail Rogut (2008). We are grateful to Paula Salvatore at Capitol Studios for help arranging many of these interviews.

20. Cole remembers, "In July 1986 I had sung 'Unforgettable' at the Newport Jazz Festival, and it had been very well received. I had experimented also with the song even before that-back in the early 1980s when I was still with Kevin Hunter and in Las Vegas, starting to work with an orchestra. I sang the song live with a reel-to-reel tape of Dad's voice backstage. The reel-to-reel was piped through the speakers onstage and Dad's voice would come on. Then they'd push the mute button and the orchestra would start playing. We had a little click track so that the band would start at the same time the tape did. Dad's voice would come through the house and then they'd mute his voice along with the track while the live orchestra kept playing. First Dad would sing 'Unforgettable, that's what you are,' and then I would sing 'Unforgettable, though near or far.' (It was rather crude, technologically, but it worked.) The audiences were so moved that I backed away from doing it more than a few times. Singing that song stopped the show. It completely changed the mood and left me with nowhere to go as a performer" (Cole and Diehl 2000:229). 
Foster and his engineer, David Reitzas, used the tape to work up a rough sketch of the tune in Foster's home studio in Malibu. Using synth pads and keyboards, the two mapped out the song and expanded on Natalie's plan for the vocal exchanges that would occur between the singer and her father. From there, they took the tape, complete with Nat's vocal on track 3 and their synth and keyboard scratch tracks, to another studio in Hollywood. ${ }^{21}$ There, they "bounced," or rerecorded, Nat's vocal line to track 18 , muting those sections of his performance that would later be sung by Natalie. On those sections where Nat was still singing, the engineers had to address the fact that his isolation on the center track of the 1961 master was not completeghostly traces of the original orchestral accompaniment had seeped onto his vocal track. The engineers used analog filters "to try to strip it clean," Schmitt remembers. "We filtered out as much as we could with filters, not touching the voice. And then [...] we edited out the spaces in between [individual phrases]" (2007). It bears noting that this technique of revertibility is virtually identical to that undertaken in 1932 for Caruso's "Vesti la Giubba."

Yet the isolation pursued through this round of stripping was still incomplete, and Mandel's arrangement for the 1991 recording was dictated at certain moments by the need to cover up or match Riddle's. As Reitzas explains, "When Nat was singing, Johnny Mandel, the arranger, needed to stay similar with the [original] arrangement, because otherwise, you'd hear the leakage on his vocal mic, and it would sound weird. But when Natalie was singing, there was obviously no leakage, so he had more freedom to change the arrangement" (2008). The 1961 accompaniment is thus present in the 1991 version, acoustically as a (barely) audible palimpsest and formally as a framework upon which Mandel created his (barely) new arrangement. ${ }^{22}$

Mandel's adaptation is one of many techniques used to facilitate matching between the two recordings, an objective that continued when the engineers recorded the orchestral and rhythm tracks in February 1991 at Ocean Way Studio in Hollywood (Natalie was also on hand to sing with the orchestra and record a scratch vocal track). Matching is crucial to this discussion not simply because the marketing campaign for the album stressed its fidelity to the ethos of 1940s and '50s crooning (signaled on the album's cover through Natalie's white satin dress, an image that evokes the glamour of 1940s Hollywood as well as the elegant lining of a coffin). George Hurrell, the legendary 86-year-old Hollywood photographer, agreed to come out of retirement to shoot Natalie in the dramatically lit style of the '40s (Foster 1991). If, as we have argued, deadness is emplacement within a concatenation of displacements, then matching itself is a crucial and active technique for traversing the topologies of deadness. ${ }^{23}$ More than mere mimesis, matching is a method for reactivating the latent capital stored in recorded performances; it is a form of managing the complex spatialities and temporalities of the intermundane. Significantly, matching is a shared process that is co-performed here by entities in 1991 and 1961 (and not simply a certain fidelity to an inert aesthetic past, or a pact with the commercial value of the "authentic"). In the case of the sessions at Ocean Way, we can point to four

21. We are grateful to Al Schmitt for sharing tracksheets of these sessions with us.

22. The similarities between Mandel's arrangement for the 1991 recording and Riddle's original arrangement was the subject of a 1994 lawsuit brought by Riddle's widow against Elektra records. Naomi Riddle claimed that "that 87 percent, or all but $81 / 2$ of 69 bars of the 1991 version, are identical to those of the original," and that Elektra had failed to give Riddle proper recognition (and proper remuneration). Citing a trademark infringement, she sought $\$ 2$ million in damages (Tabor 1994). The suit was settled for an undisclosed amount, and on subsequent pressings of the CD, Riddle was listed as "arranger," with Mandel given credit for "adaptation of original arrangement."

23. The desire to match is not always matched by historiographic accuracy. Again and again, for example, Nat's original performance is mis-placed by writers to Capitol Studios in Los Angeles, rather than the 46th Street Studio in New York City where it actually occurred (this lapse can be found in Buskin [2004], and even in the liner notes to Unforgettable, with Love). There seems to be a need for temporal disjointedness to be balanced with spatial cotermineity: if there is a 30-year gap in the performances of father and daughter, there shouldn't be a 3000-mile gap separating the locations of those performances. 
examples of matching: temporal synchronization, hand-limiting, microphone selection, and personnel decisions.

In order to synchronize the 1991 performers to Nat's pre-recorded vocal, the producers and engineers created a click track. By this time, clicks had become commonplace in popular music production, and were usually generated by mechanical means. This was not the case in 1961, however-though click tracks were ubiquitous in film production, they had not yet made the jump to projects focused purely on music recording, and the slight yet perceptible tempo fluctuations on Nat's original performance bear this out. ${ }^{24}$ As Schmitt explains, in order to match these fluctuations, they generated a "human click": "[A] famous old drummer named Sol Gubin, who'd played a lot of Sinatra dates, put a human click on it for the orchestral musicians to work to-as the Nat Cole recording had been made without a click, the tempos obviously varied quite a bit [... W] e had the full orchestra play—and Natalie sing- to [...] Sol's human click" (in Buskin 2004). If Nat's sense of time had an effect on the 1991 performance (both technologically and musically), so too did specific engineering techniques prevalent before the development of much of the effects units available for the 1991 session. For example, in the 1950s, Schmitt had developed particular choreographies for dealing with challenges created by amplitude fluctuation in vocal performance. As he told Sound on Sound: "Way back, when I started in the business, we didn't have limiters to use on the vocal, so we did most of the limiting by hand. You learned the song quickly, and where the artist got big you were able to pull back the level, while you'd increase it where the artist got softer. Since I think this approach produces better results, I still work mostly that way [...]" (in Buskin 2004). The practice of hand-limiting, though supplemented in 1991 by what Schmitt calls "a tiny amount of Summit limiter" (which automatically manages amplitude spikes), effectively extends the "past" of recording history into the present by drawing on Schmitt's experience as an engineer in the 1950s and '60s. Schmitt also paid close attention to matching the grain of Nat and Natalie's voices. The Neumann U67 microphone they chose for her voice not only aligned with the warm sound of classic recordings, but also melded with the $\mathrm{U} 47$ that Nat had used 30 years prior. Finally, in addition to these processes of synchronization, hand-limiting, and microphone selection, the desire to match also manifests itself at the corporeal level through the contracting of musicians who were active during the time of the 1961 session. Some of these performers had even collaborated with Nat while he was still alive. "It was no coincidence that many of the musicians were the original players on my father's recordings," comments Natalie in her liner notes to the album..$^{25}$

Another move, another place, another time. Soon after the Ocean Way session, Natalie entered another isolation booth, this time at Johnny Yuma Studios, where she laid down the final vocal tracks. As with any recording, the isolation was not total-other sessions, other times, and other spaces leaked into and out of this room. At this particular session, the focus of attention was on the voices of Nat and Natalie. This is where the structure of their duet was finalized. Natalie did a number of takes that were distributed across 3 different tracks $(15,17$, and 23). To mix these to a "composite track" (track 16), Schmitt and Reitzas used a custom-built device specifically designed to cross-fade together different takes, folding together the best bits from each run-through (which were each punched-in composites themselves). This "comp box" facilitated another kind of matching, one of Natalie to herself. Her single performance heard

24. For the 1991 project, the human-performed sync among musicians was paralleled by the machine-performed sync of SMPTE timecode, which synchronized two 24-track machines used on the project and allowed accurate transfer between them. Timecode also facilitated GML automation at the mixdown stage.

25. Arrangers such as Ralph Burns and Bill Holman, who had fashioned charts for popular big bands during the 1940 s and 1950s, were brought in to provide the project with "authentic flavor" (Buskin 2004). Engineers like Armin Steiner, who recorded many of the album tracks at Fox Sound Studios, and Schmitt, who handled mixing on the project, maintain a recording sensibility that privileges the "live," or non-overdubbed (Steiner 2008; see also Droney 2001). 
on the final recording is an assemblage of many performances, and although Natalie records from a single location, multiple times are folded into the final product.

Like the comp box, the AMS DMX 15-80s Computer Controlled Stereo Digital Delay played a key role at this stage of the recording process. Schmitt and Reitzas had loaded a few phrases of Nat's performance into the machine, and used it as a sampler to digitally tune his voice to the 1991 orchestral tracks. It was only a matter of a few cents for a few phrases, Reitzas recalls, yet Schmitt still felt "a little strange" (2007) adjusting the original track (he called this process "unforgivable" [in Buskin 2004]). They also used the AMS unit to create the song's memorable third verse, in which Nat responds to his daughter phrase-by-phrase. Significantly, Natalie leads this temporally complex duet, with her father's contribution now taking the form of an echo. An echo? No, a pre-echo, sounding ahead from the past. Natalie recalls, "At one point, David [Foster] thought, 'Wouldn't it be incredible if not only she answers her father but be answers her, as though he was right over her shoulder?' The next morning he went into the studio with Al Schmitt, engineer extraordinaire, and figured out the technical aspect of laying Dad's voice inside the new track and moved it. As it happened, the chords worked perfectly, so he could lay Dad's voice in later. It was as though Dad had come in and redone the vocals" (Cole with Diehl 2000:246). The chords may have worked well, but the orchestral figures presented some difficulties once they had been temporally displaced. Since the decision to move Nat out of his original phrasal position in the tune was made after Mandel had written and recorded his orchestral accompaniment, they couldn't just ask him to do a new arrangement that would cover up (or re-bury) the displaced lines. Instead, as Reitzas recalled, he and Schmitt performed a second round of stripping on Nat's voice to remove as much of the 1961 ghost orchestra as possible- "Filtered it out," he explained, "then added a little more top end back on" to restore the sheen that had been worn away from the voice by excessive equalization (Reitzas 2008). The engineer's operations here demonstrate how one distinct time (the vertical relation between voice and accompaniment) can be split to occupy two temporal locations. The temptation might be to think of this move in terms of schizophonia, but the lingering traces of anterior sonic events always effect proleptic, rhizophonic relationships with other sonic futures.

In the interplay between Nat and Natalie that emerges in the third verse-and in their duet as a whole - their voices are $\mathrm{im} / \mathrm{material}$ parts of bodies that are distributed, noncontinuous, and overlapping. To understand this intermingling in the terms of corpaurality, we must hear the voice emerging from the resonant body as the body resonates in the voice. Dislocated from the fleshy body, the voice nonetheless bears its entwined imprint; in mapping this negative presence, we encounter Avery Gordon's project of examining ghostly matters: "where finding the shape described by her absence captures perfectly the paradox of tracking through time and across all those forces that which makes its mark by being there and not being there at the same time" (1997:16). The voice's materiality is not simply a trace of a prior corporeality but is an emergent, interactive dialogic presence. As these two corpauralities draw together in the final mix, this meeting of mouths - this kiss, this touch-between father and daughter concretizes a number of articulations and absorptions (fig. 1). The mouth is an opening of sound and flesh, ${ }^{26}$ and as Judith Butler observes, "the flesh is not something one has, but, rather, the web in which one lives," and touch "cannot be reducible to a unilateral action performed by a subject" (2004:181). Where does one body—one sound—begin and the other end, and in what ways do sounds gather up the world, absorb and form the bodies they meet? Nat sings of "a love that clings to me," and it is clear that the sonic is also haptic, and that haptic sonicities can cut across the mundanities of living and dead. As Natalie recalls, describing her experience singing with her

26. See Merleau-Ponty (2004): "What is again open to us, therefore, with the reversibility of the visible and the tangible, is - if not the incorporeal — at least an intercorporeal being, a presumptive domain of the visible and the tangible, which extends further than the things I touch and see at present" (259). 
father in the recording studio, "I felt as if he was more communicating with me, that he was kind of leading me in all the right things. And we were kind of holding hands" (Cole 1991b).

During the mixing process, which took place at yet another location, the Bill Schnee Studio in North Hollywood, Schmitt and Reitzas continued to facilitate vocal matching by attending to resonance-reverb and echo. Schmitt recalls:

In terms of matching room sound, I changed the echo around a little bit-with Nat, the echo was on his voice, but I also added to it so that it matched up with Natalie's sound [...]. The consoles back in those days had very little; they didn't have the compressors or gates that we're now used to, so what you hear is his natural voice, and on "Unforgettable" it sounded absolutely huge. As a result, one of the problems we had was trying to get Natalie to match that, and that took a lot of work, trying to duplicate the echoes and levels and so forth. (in Buskin 2004)

Functionally, the digital effects units that Schmitt used to achieve this matching are identical to architectural echo chambers like the celebrated chambers 30 feet below the Capitol Records Tower in Hollywood (which were not used on this project). As with these celebrity crypts, digital reverb machines reanimate (or enliven) sounds that are dead (or not-yet-born) and return them to tape. Cables carry these signals and transmit them through portals, and the result is a kind of sonic "rapport," which is nothing more than carrying something back through an opening or portal.

And rapport, consonance through resonance, is the fundamental mark of the intermundane. On "Unforgettable," the rapport (or co-laboring) of dead and living engineers, musicians, and sounds is configured within a resounding network of resonant revenants. Though the collaboration between Natalie and Nat is most conspicuous, the intermundanity of the track extends to the orchestral arrangements (where scoring decisions made by Riddle in his 1951 arrangement effect a covering up by Mandel in 1991) and to the recording sensibility (which provides a sonic contact zone for engineers of both eras). We don't know the identities of the engineers on the 1961 session but traces of their labor-mic placements, hand-limiting, gear choice—surely intersect with the work of the 1991 engineers. In our interview, Reitzas asserted that he and Schmitt were the sole engineers for the vocal tracks, start to finish, but he was quick to add, "And whoever recorded Nat's vocals." During the 1991 sessions, musicians, engineers, arrangers, and producers - all essential to the making of the final product — engaged with each other across various kinds of segmentations, both spatial and temporal. This variegated form of engagement is what we call deadness.

\section{The Responsive Co-Labors of Deadness}

Deadness produces the resonances and revenances that condition all modes of sonic performance. We engage deadness not as displacement, but as emplacement in layered, rhizophonic sites of enfolded temporalities and spatialities. Within these sites, laborers are corpaural, bodies are always sonic bodies.

In the context of intermundane collaborations, liveness is enabled by the productive capacities of deadness, the distributed and noncontinuous temporalities effected by the body's translation and proliferation through recording technology. ${ }^{27}$ What is called liveness is nothing more than a transitive effect of deadness, and deadness is nothing more than the promise of recombinatorial and revertible labor. In the particular circulation of effectivity that characterizes intermundanity, the living register the effective co-presence of the dead even as they draw and

27. Unlike Philip Auslander (1999), we see liveness as co-constituted with deadness not as the result of mediatization, but rather as the necessary labor arrangement of intermundanity. Media is not merely a connective technology between agencies, but is itself an effective agent. 
obdurate an impossible separation between mundanities. Collaboration is thus a sympathetic consonance structured in inequality, and skirmishes over rights inevitably arise. ${ }^{28}$

Within the economies of music production in the US, the co-laboring of the living and the dead hits its productive stride in the 1950s, when a general recombinatorial imperative achieves normative status, and sonic labor becomes ever more revertible. In the labor disputes that precede this decade, musical workers began regularly referring to themselves as "living" or "live" musicians, indicative of the lines along which they responded to the re-formation of the music industry from an entertainment model based on performance to a mass media economy based on reproduction, stockpiling, and repetitive playback (see Anderson 2006; Attali 1985; and Thornton 1995). "Living" musicians could now record "live"-indeed, in our conversations with Schmitt and Armin Steiner (who recorded many of the other tracks for the Unforgettable album), both of whom came of age professionally in the 1950 s, liveness surfaces again and again as the preferred mode of musical co-labor: "I prefer that," Schmitt comments, "but that's just because that's the way I grew up, with everything live" (2007); while Steiner declares, "I'm a live person. I like to do things live" (2008).

\section{In these intermundane collaborations, agencies emerge from all directions in a network, and personhood is performed far beyond the epidermal wall.}

But as live persons are extended and proliferated through recording technologies and practices, they constantly collaborate with the dead and the not-yet-born. Moreover, through recording itself, these live persons sign on to future networks where they will play a decidedly different role. They are the becoming dead. In these intermundane collaborations, agencies emerge from all directions in a network, and personhood is performed far beyond the epidermal wall. The living can make no special claim on effectivity, nor do they necessarily maintain a relationship of dominance with the dead (even though in the economies of late capitalism the particular effectivities of the living are often used to exploit the productive capacities of the dead). The effective agencies that we attribute to individual persons are always distributed across multiple mundanities and always involve co-labor.

As any material history of sound recording makes clear, the role played by technology cannot be overstated. Microphones, cables, tape heads, headphones, and architectures not only enable and enhance the effectivity of the living and the dead; they take on a formative role in these contingent arrangements. We are offering a model of collaboration, then, that moves beyond the interaction of human workers, whether living or dead, to register rapport among all entities that have effects. With this model, we recognize that collaboration transpires along differential axes of access, emplacement, privilege, capacity, and responsibility. Collaborations like the posthumous duets discussed in this article are built upon the restricted, yet still effective, motile emplacements of dead and living humans within mundanities teeming with all kinds of active non-humans.

The technological is not the only topology of the intermundane. The networks in which these technologies do their work are always also legal, economic, familial, affiliative, and corporate. For example, familial claims are often significant in intermundane collaborations, and inevitably lead to a cluster of questions-who has a right to make such a claim, how will the claim be administered financially, and so on. Again, the politics of access are paramount. Under US estate law, which is structured primarily around kinship ties, family members of deceased artists often have a heightened ability to secure the rights to original master recordings (intestate law makes it impossible for the dead to own property). In the case of recordings that are not 
controlled by the artist or the artist's family, corporate entities are typically more willing to give family members permission for access to original recordings because of the forceful place blood ties have within marketing structures dominated by celebrity. Matching thus rears its head again, this time within the realm of genetic ties and the corporate arrangements that harness these ties. In the case of "Unforgettable," family ties are crucial, if contested. Natalie's mother, Maria, has voiced reservations about the duet, admitting that she "[doesn't] like to listen to [Natalie's version]. I just feel that everything belonged to him" (fet 1992:34). "Belonging" here, however, is shot through with betrayal. Less than a year before the "Unforgettable" recording session, Natalie and her four siblings learned that Nat had set up a trust fund for the children before his death, a fund that had been concealed from them for many years by their mother (Cole with Diehl 2000:290-303). Because the Cole family was earning \$500,000 in royalties per year from Nat's posthumous sales, the familial and financial stakes of "Unforgettable" were high. The runaway success of the album no doubt raised them even further, and in 1995, Maria sued her five children for their portion of Nat's estate (the suit was settled out of court in 1998). Though partially incapacitated by his death in 1965, Nat acts at the center of these legal struggles, and his position indicates that flesh is not the only "web in which one lives." The story is more complex than this, but for now we should emphasize that the effectivity of singing ghosts in the techno-sonic realms of the intermundane is at least partially determined by rapidly changing laws governing the transference of wealth and property.

Family squabbles in cases like these are thus weighted with enormous financial consequences, and often lead to the denunciation of intermundane collaborations as enterprises of the living for exploiting the dead, as if only the former have agency in these exchanges. ${ }^{29}$ Though ostensibly concerned with defending the memory of the dead, this objection betrays a failure to register their agency, their effectivity within a mundanity from which they seem to have been banished. Just as we can never completely predict our own effects in the world, so too can we never completely foreclose the effectivity of another entity. Nonetheless, asymmetries of power-and thus of responsibility - persist. We argue that collaborations with the dead are no different in this regard than those with the living, and we should be careful not to condemn intermundane projects out of hand. Such quick judgments can harbor the implicit assumptions that relations between the living are always ethical, or even symmetrical in terms of rights and privileges -both plainly not the case. To the extent that we have effects on other entities, these other entities also have effects on us. Being mindful of this mutual effectivity, this intra-action and co-creation of agential formations, means taking responsibility for a responsive effect. The difficult problem, the impossible question, is whether we can expect a responsive ethics, a resonant ethics, from all things that have effects.

This question is different than the one raised by Fred Moten: "What is your ethical responsibility to the object, what is your ethical responsibility to that insurgency of the object?" (in Cahill and Thompson 2005:51). It is far more drastic and it's not "What is the object's ethical responsibility to you?" Rather, our concern is to question what an ethics of effects might look like, one that reaches outside of the customary contact zones that are rendered along (dis) alignments of subjects and objects, and counters the stock notion that ethics is solely a human concern. The conundrum we encounter has to do with the extent to which we risk reinstating a human exceptionalism along the ethical axis that we have worked so hard to neutralize along the agentic. All entities have effects. Do all entities have ethics? What kinds of co-responsibility do the disparate yet mutually effective worlds of humans and nonhumans, material and immaterial entities, and the living, dead, and not-yet-born have for one another?

We have arrived at the idea that the worlds referenced in the term "intermundane" are co-responsive but not always co-responsible. But the "inter" in intermundane-itself suggest-

29. See, for example, Pat Metheny's notorious criticism of Kenny G’s "What a Wonderful World” collaboration with Louis Armstrong (Metheny n.d.), as well as Goodman (2000). 
ing, paradoxically, both reciprocal exchange and one-way entombment-betrays the complex processes of encounter that we've been speaking of here. Worlds of objects, humans, and nonhuman life do something other than simply "inter"-act and, indeed, a conception that posits mutually exclusive, ethically misaligned worlds, self-sufficient and ontologically stable, is not what we're after. These "worlds" do not preexist their enrollment in contingent assemblages; it is in and through reciprocal effectivity-collaboration-that they take shape. In the words of Donna Haraway, "The relationship is the smallest possible pattern of analysis" (2008:25-26). The term "intermundane" might better index all relationships between entities that are nonidentical, but whose identities seem to be mutually instrumental. In late capitalism, deadness has emerged as a decisive patterning of intermundanity based upon ever-replenishable value, ever-resurrectable labor, ever-revertible production processes. Far from being anomalous, posthumous duets amplify and reverberate these ubiquitous acts of deadness.

\section{References}

Anderson, Joel. 2004/2005. "What's Wrong with this Picture?: Dead or Alive: Protecting Actors in the Age of Virtual Reanimation.” Loyola of Los Angeles Entertainment Law Review 25, 2:155-202.

Anderson, Tim J. 2006. Making Easy Listening: Material Culture and Postwar American Recording. Minneapolis: University of Minnesota Press.

Attali, Jacques. 1985. Noise: The Political Economy of Music. Trans. Brian Massumi. Minneapolis: University of Minnesota Press.

Auslander, Philip. 1999. Liveness: Performance in a Mediatized Culture. London: Routledge.

Barad, Karen. 2007. Meeting the Universe Halfway: Quantum Physics and the Entanglement of Matter and Meaning. Durham: Duke University Press.

Beard, Joseph J. 1993. "Casting Call at Forest Lawn: The Digital Resurrection of Deceased EntertainersA 21 st-Century Challenge for Intellectual Property Law.” Berkeley Technology Law Journal 8, 1. www.law. berkeley.edu/journals/btlj/articles/vol8/Beard.pdf (11 October 2009).

Beard, Joseph J. 2001. "Clones, Bones, and Twilight Zones: Protecting the Digital Persona of the Quick, the Dead, and the Imaginary.” Berkeley Technology Law fournal 16, 3:1165-271.

Buskin, Richard. 2004. "Classic Tracks: 'Unforgettable.” Sound on Sound, January. www.soundonsound.com/ sos/jan04/articles/classictracks.htm (11 October 2009).

Butler, Judith. 2004. "Merleau-Ponty and the Touch of Malebranche." In The Cambridge Companion to Merleau-Ponty, eds. Taylor Carman and Mark B.N. Hansen, 181-205. Cambridge: Cambridge University Press.

Cahill, James Leo, and Rachel Leah Thompson. 2005. "The Insurgency of Objects: A Conversation with Fred Moten." Octopus 1 (Fall):45-66. http://yoda.hnet.uci.edu/fvc/vsgsa/octopus/octo_archive/ vol-01-f2005/toc.html (9 October 2009)

Carmichael, Ralph. 2008. Telephone interview with authors, 29 August.

Castronovo, Russ. 2001. Necro Citizenship: Death, Eroticism, and the Public Sphere in the Nineteenth-Century United States. Durham: Duke University Press.

Chakrabarty, Dipesh. 2000. Provincializing Europe: Postcolonial Thought and Historical Difference. Princeton: Princeton University Press.

Cogan, Jim, and William Clark. 2003. Temples of Sound: Inside the Great Recording Studios. San Francisco: Chronicle Books.

Cole, Natalie. 1991a. "Unforgettable." On Unforgettable with Love. Elektra 61049-2.

Cole, Natalie. 1991b. Unforgettable. Steve Barron, dir. New York: Elektra Video.

Cole, Natalie, with Digby Diehl. 2000. Angel on My Shoulder: An Autobiography. New York: Warner Books.

Davis, John P. 1963. "A Multi-Purpose Studio Recording System.” Journal of the Audio Engineering Society $11,4: 360-70$.

Derrida, Jacques. 1994. Specters of Marx: The State of the Debt, the Work of Mourning, and the New International. Trans. Peggy Kamuf. New York: Routledge. 
Doyle, Peter. 2005. Echo \& Reverb: Fabricating Space in Popular Music Recording, 1900-1960. Middletown: Wesleyan University Press.

Droney, Maureen. 2001. “Armin Steiner.” Mix, 1 May. http://mixonline.com/mag/audio_armin_steiner/ (11 October 2009).

Eisenberg, Evan. [1987] 2005. The Recording Angel: Music, Records and Culture from Aristotle to Zappa. New Haven: Yale University Press.

Farber, Jim. 1999. "Following in Biggie Small's Tracks.” (New York) Daily News, 7 December.

Foster, Catherine. 1991. "Natalie Brings Smooth Sounds of Nat King Cole To a New Generation." Christian Science Monitor, 30 August.

Frayne, John G., A.C. Blaney, G.R. Groves, and H.F. Olson. 1976. "A Short History Of Motion Picture Sound Recording in the United States." SMPTE fournal 85:515-28.

Fuss, Diane. 2003. "Corpse Poem.” Critical Inquiry 30:1-30.

Galloway, Alexander R., and Eugene Thacker. 2007. The Exploit: A Theory of Networks. Minneapolis: University of Minnesota Press.

Gardner, Eriq. 2006. "Cult of Personalities.” IP Law and Business 4, 1:50.

Goodman, Fred. 2000. "Duets with the Dead: Homage or Exploitation?” New York Times, 16 January.

Gordon, Avery F. 1997. Ghostly Matters: Haunting and the Sociological Imagination. Minneapolis: University of Minnesota Press.

Guernsey, Lisa. 2001. “Software Is Called Capable of Copying Any Human Voice.” New York Times, 31 July.

Guthrie, Jonathan. 2005. "To Cut Costs and Reduce Risk Use a Dead Celebrity.” Financial Times, 27 April.

Haraway, Donna J. 2008. When Species Meet. Minneapolis: University of Minnesota Press.

Hilburn, Robert. 1981. “Jim Reeves, Patsy Cline: 'Duet' Lives.” Los Angeles Times, 14 November.

Hochheiser, Sheldon. 1992. "What Makes the Picture Talk: AT\&T and the Development of Sound Motion Picture Technology." IEEE Transactions on Education 35:278-85.

Hoffman, Leah. 2005. "Agents of the Dead." Forbes, 31 October.

fet. 1992. "Natalie Cole Gains New Fame with Father's Music Even Though her Musical Mother Disapproves." Fet, 24 February.

Joel, Irv. 2008. Telephone interview with authors, 10 September.

Jones, Steve, and Joli Jensen, eds. 2005. Afterlife as Afterimage: Understanding Posthumous Fame. New York: Peter Lang.

Kraft, John P. 1996. Stage to Studio: Musicians and the Sound Revolution, 1890-1950. Baltimore: Johns Hopkins University Press.

Latour, Bruno. 2005. Reassembling the Social: An Introduction to Actor-Network-Theory. New York: Oxford University Press.

Laurens, Rhett H. 2001. "Year of the Living Dead: California Breathes New Life into Celebrity Publicity Rights." Hastings Communications and Entertainment Law fournal 24:109-47.

Leigh, Spencer. 2006. "Bill Miller; Sinatra's Arranger and Accompanist.” The Independent, 18 July.

Levinson, Nathan. 1933. "Rerecording, Dubbing or Duping." American Cinematographer 13, 11:6-7.

Melloy, Neil. 1999. "Celine’s Family Affair.” Courier Mail (Queensland, Australia), 13 September.

Merleau-Ponty, Maurice. 2004. “The Intertwining_The Chiasm.” In Maurice Merleau-Ponty: Basic Writings, ed. Thomas Baldwin, trans. Alphonso Lingis, 247-71. London: Routledge.

Metheny, Pat. n.d. "Pat Metheny on Kenny G.” www.jazzoasis.com/methenyonkennyg.htm (18 December 2008).

Millard, Andre J. 1995. America on Record: A History of Recorded Sound. Cambridge: Cambridge University Press.

Morton, David. 1995. “The History of Magnetic Recording in the United States, 1888-1978." PhD diss., Georgia Institute of Technology. 
Morton, David. 2000. Off the Record: The Technology and Culture of Sound Recording in America. New Brunswick: Rutgers University Press.

Morton, David. 2004. Sound Recording: The Life Story of a Technology. Westport: Greenwood Press.

New York Times. 1926. "Marvels of the Vitaphone.” New York Times, 25 July.

Noer, Michael, David M. Ewalt, and Peter Hoy, eds. 2008. “Top-Earning Dead Celebrities.” Forbes, 27 October. www.forbes.com/2008/10/27/dead-celebrity-earning-biz-media-deadcelebs08_cx_mn_ de_1027celeb_land.html (9 October 2009).

O'Brien, Charles. 2005. Cinema's Conversion to Sound: Technology and Film Style in France and the U.S. Bloomington: Indiana University Press.

Pakenham, Compton. 1932. "Newly Recorded Music.” New York Times, 23 October.

Parmenter, Ross. 1941. "Records: Gypsy Music.” New York Times, 13 July.

Pathé Pictorial. 1932. "Voice Grafting: the Latest Miracle of 'Sound' Science.” British Pathé. www. britishpathe.com/record.php?id=28993 (11 October 2009).

Peterson, Christopher. 2007. Kindred Specters: Death, Mourning, and American Affinity. Minneapolis: University of Minnesota Press.

Putnam, Milton T. 1980. "A Thirty-five Year History and Evolution of the Recording Studio." Audio Engineering Society Preprint 1661. www.aes.org/aeshc/pdf/putnam_history-of-recording-studios.pdf (11 October 2009).

Rayner, Alice. 2006. Ghosts: Death's Double and the Phenomena of Theatre. Minneapolis: University of Minnesota Press.

Reitzas, David. 2008. Telephone interview with authors, 27 August.

Rettinger, Michael. 1957. "Reverberation Chambers for Broadcasting and Recording Studios." Journal of the Audio Engineering Society 5, 1:18-22.

Roach, Joseph. 1996. Cities of the Dead: Circum-Atlantic Performance. New York: Columbia University Press.

Rogut, Rail. 2008. Telephone interview with authors, 2 September.

Schafer, R. Murray. 1977. The Tuning of the World. New York: Knopf.

Schmidt-Horning, Susan. 2002. "Chasing Sound: The Culture and Technology of Recording Studios in America, 1877-1977.” PhD diss., Case Western Reserve University.

Schmitt, Al. 2007. Telephone interview with authors, 15 September.

Schmitt, Al. 2008. Telephone interview with authors, 1 September.

Snyder, Ross H. 2003. "Sel-Sync and the 'Octopus': How Came to be the First Recorder to Minimize Successive Copying in Overdubs." ARSC Fournal 34, 2:209-13.

Steiner, Armin. 2008. Telephone interview with authors, 5 August.

Sterne, Jonathan. 2003. The Audible Past: Cultural Origins of Sound Reproduction. Durham: Duke University Press.

Strathern, Marilyn. 1988. The Gender of the Gift: Problems with Women and Problems with Society in Melanesia. Berkeley: University of California Press.

Strathern, Marilyn. 1992. After Nature: English Kinship in the Late Twentieth Century. Cambridge: Cambridge University Press.

Sutheim, Peter. 1989. "An Afternoon with Bill Putnam.” Fournal of the Audio Engineering Society 37, 9:723-30.

Tabor, Mary B.W. 1994. "Suit Calls an 'Unforgettable' Omission Unforgivable.” New York Times, 14 May.

Théberge, Paul. 1997. Any Sound You Can Imagine: Making Music/Consuming Technology. Hanover: Wesleyan University Press.

Thompson, Emily. 2002. The Soundscape of Modernity: Architectural Acoustics and the Culture of Listening in America, 1900-1933. Cambridge: MIT Press.

Thornton, Sarah. 1995. Club Cultures: Music, Media and Subcultural Capital. Cambridge: Polity Press. 
Toop, David. 1991. “Gone to Rock 'n' Roll Heaven, or Perhaps She's Stuck in Limbo.” Times (London), 26 August.

Verdery, Katherine. 1999. The Political Lives of Dead Bodies: Reburial and Postsocialist Change. New York: Columbia University Press.

Weiss, Allen S. 2002. Breatbless: Sound Recording, Disembodiment, and the Transformation of Lyrical Nostalgia. Middletown: Wesleyan University Press.

Welch, Walter L., and Leah Brodbeck Stenzel Burt. 1994. From Tinfoil to Stereo: The Acoustic Years of the Recording Industry, 1877-1929. Gainesville: University of Florida Press.

Zimmerman, David. 1993. "Emmylou Harris Offers Up a Heavenly 'Prayer.” USA Today, 12 October.

Zimmerman, David. 1989. "Hank Jr. Shares a 'Beer' with Dad.” USA Today, 2 March. 